\title{
Novel Therapies for Treating Short Stature with Congenital Adrenal Hyperplasia
}

\author{
Michael Christopher Hann, Anisha Kshetrapal, Maria I New, Joe Leigh Simpson \\ Herbert Wertheim College of Medicine, Florida International University, Florida, USA
}

Correspondence: Michael Christopher Hann, Herbert Wertheim College of Medicine, Florida International University, 11200 SW 8th Street, Miami, Florida-33199, USA, Phone: 1-305-348-0570, Fax: 1-305-348-0123, e-mail: mhann002@fiu.edu

\section{ABSTRACT}

Congenital adrenal hyperplasia $(\mathrm{CAH})$ is a group of autosomal recessive disorders in which various errors in adrenal biosynthesis pathways lead to impaired cortisol secretion, possible impairment of mineralocorticoid production and androgen excess. Glucocorticoid replacement therapy is the primary treatment for $\mathrm{CAH}$; however, the combination of androgen excess and high doses of glucocorticoids contributes to shortened adult height. Novel approaches to address this problem are being developed, particularly the use of growth hormone (GH) and gonadotropin releasing hormone analogs $(\mathrm{GnRHa})$. In this review, we document and compare the effectiveness of these novel therapies in ameliorating the decreased adult height observed in patients with $\mathrm{CAH}$. Available data indicate effectiveness of these novel treatment strategies, suggesting widespread implementation of these treatment strategies should be tested with the expectation of being recommended as the standard of care.

Abbreviations: Congenital adrenal hyperplasia (CAH); Salt wasting (SW-CAH); Non-salt wasting (NSW-CAH); Growth hormone (GH); Gonadotropin releasing hormone analogs (GnRHa); Luteinizing hormone releasing hormone analog (LHRHa); 21-hydroxylase gene (CYP21); 21-hydroxylase pseudogene (CYP21p); Hypothalamic-pituitary-adrenal (HPA); Corticotropin-releasing hormone (CRH); Adrenocorticotropic hormone (ACTH); Bone mineral density (BMD); Standard score (SDS).

Keywords: Adrenal hyperplasia, Congenital, Gonadotropin-releasing hormone, Growth hormone, Body height.

\section{INTRODUCTION}

The current treatment for congenital adrenal hyperplasia (CAH) is glucocorticoid replacement therapy. However, if treatment is insufficient, high therapeutic doses of glucocorticoids and androgen excess resulting from hyperplastic adrenal glands invariably results in decreased final adult height. Novel approaches to address adult short stature due to $\mathrm{CAH}$ have included the use of growth hormone (GH) and gonadotropin releasing hormone analogs (GnRHa). Limited data indicate that these treatments increased final adult height compared to CAH patients receiving glucocorticoids alone. Final adult height of GH and GnRHa treated patients are within centimeters of their mean parental predicted height. ${ }^{1-4}$ The combination therapy of GH and GnRHa has a two-pronged strategy: GnRHa prevents early epiphyseal advancement and suppresses precocious puberty due to androgen excess in CAH, whereas GH counteracts the growthsuppressive effects of GnRH and supraphysiologic doses of glucocorticoids. ${ }^{1-4}$ In this review, we discuss the rationale of administering GH, GnRHa and other therapies. We consider the effectiveness of the therapies and suggest future approaches.

Date of Received: 26-01-11

Date of Acceptance: 28-04-11

Date of Publication: May 2011

\section{CONGENITAL ADRENAL HYPERPLASIA: PATHOLOGY}

Congenital adrenal hyperplasia (CAH) is a group of autosomal recessive disorders affecting the adrenal cortex..$^{5-9}$ The most common form of CAH is due to deficiency in the enzyme 21-hydroxylase (CYP21), having an incidence of 1:15,000 live births. ${ }^{7,9}$ This deficiency results from intergenic recombination between CYP21 and a closely linked pseudogene (CYP21p); responsible for more than $90 \%$ of cases due to pseudogene derived DNA sequences. ${ }^{6,7}$ Diminished expression of functional 21-hydroxylase prevents the adrenal cortex from producing sufficient cortisol. ${ }^{5,6,8,9}$ Severely decreased or absent secretion of cortisol results in decreased negative feedback on the hypothalamic-pituitary-adrenal (HPA) axis, leading to increased corticotropin-releasing hormone (CRH) and increased adrenocorticotropic hormone (ACTH). ${ }^{5,6,8}$ Increased stimulation due to elevated ACTH levels induces adrenal cortex hyperplasia leading to precursors that are shunted into the androgen synthetic pathway (Fig. 1) $)^{5-9}$ Increased glucocorticoid precursors thus lead secondarily to androgen excess (androstenedione), which may be converted to testosterone and virilize the external genitalia of female fetuses affected with CAH. ${ }^{6,7,9,10}$

\section{Clinical Presentation}

21-hydroxylase deficiency exists in classical and non-classical forms. The molecular basis underlying this difference is 
discussed in detail elsewhere. ${ }^{9,11-18}$ Briefly, classical CAH is more severe and is further stratified into salt wasting (SW-CAH) and non-salt wasting (NSW-CAH) forms. ${ }^{5-7,9}$ In SW-CAH, excess secretion of 17-hydroxyprogesterone and progesterone results in a salt-wasting tendency ${ }^{19}$ (see Fig. 1) with the zona glomerulosa being unable to produce aldosterone; then, salt-wasting crises arise. ${ }^{7,8}$ With more moderate deficiency in 21-hydroxylase, the adrenal cortex can produce sufficient aldosterone to compensate, and hence maintain a relatively normal sodium balance (NSW-CAH) ${ }^{7,8}$ The non-classical form of $\mathrm{CAH}$ is even less severe, usually only presenting as precocious pubarche and advanced bone age in children. ${ }^{5-7,9}$

\section{Bone Integrity and Glucocorticoid Treatment}

Glucocorticoid treatment has been associated with various complications. At supraphysiologic doses, glucocorticoid replacement levels have been shown to result in diminished bone accrual, leading to osteopenia and osteoporosis. ${ }^{20}$ However, unlike other diseases that require glucocorticoid replacement therapy, treated CAH patients have not demonstrated a detrimental effect of glucocorticoid therapy on bone mineral density (BMD). ${ }^{21-26}$ The mechanism as to why bone loss does not occur in CAH remains unclear, but it is postulated that elevated androgens typical of CAH may have a protective effect on bone integrity. $5,6,23$

\section{Height and Glucocorticoid Treatment}

Most CAH patients achieve a final adult height that is shorter than predicted from mean parental height, regardless of the age at diagnosis or the quality of endocrine treatment. ${ }^{2,6,8,16}$ The final height of CAH patients is typically between 1 and 2 standard deviations of normal height within a control population. ${ }^{27} \mathrm{~A}$ meta-analysis of 18 studies conducted between 1977 and 1998 in a total of 561 CAH patients revealed

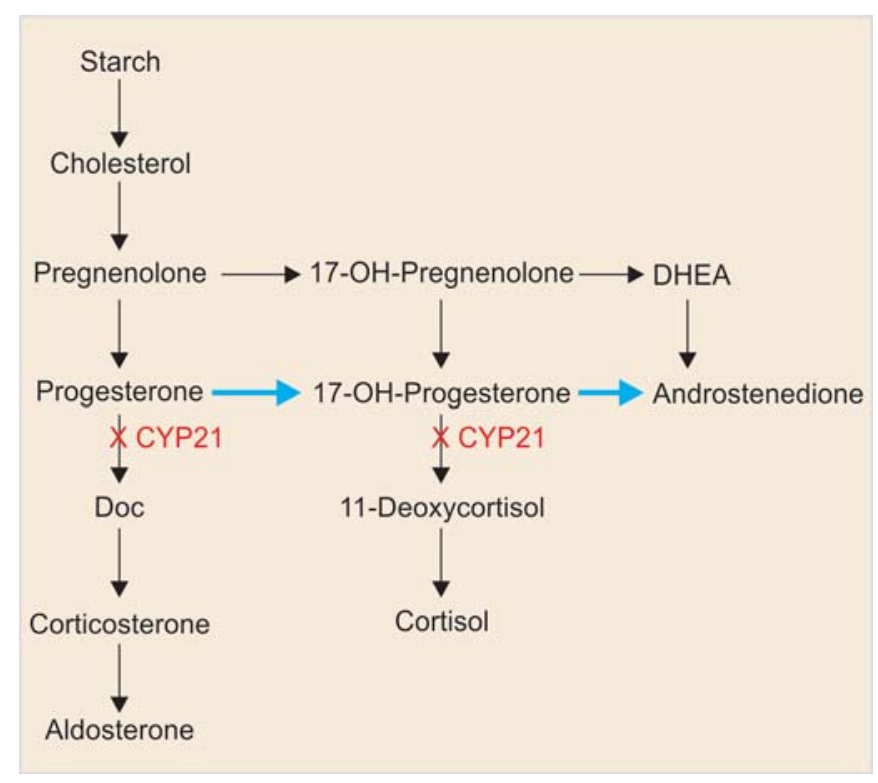

Fig. 1: Pathways for steroid biosynthesis in the zona fasciculata of an adrenal cortex with CYP21 deficiency that the mean standard score (SDS) of CAH patients was in the lower range of normal limits ( -1.37 in all, 1.57 in males and - 1.24 in studies which had at least 10 subjects with adequate females). ${ }^{27,28}$ In general, males with NSW-CAH have the worst height prognosis. ${ }^{27}$

Various explanations have been posed, but the major contributor to short stature in CAH is believed to be deleterious effects of androgen excess on bone age. ${ }^{22,23,29}$ The primary androgen hypersecreted in patients with CAH is androstenedione. ${ }^{8}$ Androstenedione does not bind to the androgen receptor itself, but 5 to $15 \%$ can be metabolized to testosterone and dihydrotestosterone. ${ }^{8}$ These potent androgens are produced in excess, probably even in ostensibly well-controlled cases. This leads to virilization and accelerated growth and advanced bone age. ${ }^{8,17}$ Aromatase converts testosterone to estradiol, which exerts its effect on the epiphyses and leads to advanced skeletal maturation and early epiphyseal fusion. ${ }^{8,17}$ Insufficient glucocorticoid administration in $\mathrm{CAH}$ patients thus leads to advanced bone age and reduced final height. ${ }^{17}$

Glucocorticoid treatment alone at physiologic doses has a suppressive effect on growth. $2,5,6,17,20,30-40$ Thus, height is decreased. Moreover, common glucocorticoids used to treat CAH in the United States are the synthetic glucocorticoids prednisolone and dexamethasone, both are more growthsuppressive compared to hydrocortisone..$^{15,17,39}$ Specifically, treatment of $\mathrm{CAH}$ with high doses of prednisolone and dexamethasone during infancy and pubertal development has been shown to compromise growth later in life. ${ }^{1,17,39}$ The reason is that therapeutic doses of glucocorticoids increase hypothalamic somatostatin tone, ${ }^{41}$ resulting in inhibition of GH secretion that normally peaks during puberty. In $125 \mathrm{CAH}$ cases who presented with reduced final adult height, additional data concerning development during infancy, childhood and puberty, and administered glucocorticoid doses were available. ${ }^{17}$ Hydrocortisone dose at the onset of puberty correlated negatively with final adult height. ${ }^{17}$ Surprisingly, prepubertal undertreatment was apparently not responsible for poor pubertal growth because bone age was within 1 year of chronological age in more than two-thirds of the patients. ${ }^{17}$ Although glucocorticoid administration requires careful monitoring and adjustment, ${ }^{1,10,17}$ patients frequently suffer from inadvertent hypercortisolism as result of excessive glucocorticoid supplementation. ${ }^{22}$ For this reason, lower glucocorticoid doses are preferred during infancy. ${ }^{17,39}$ Traditionally, adjustments to glucocorticoid doses have been solely based on growth parameters, such as body weight or surface area. ${ }^{39}$ However, it has now been established that biochemical and growth parameter monitoring is preferable to adjustments based solely on growth parameters. Biochemical parameters used for evaluation of therapy include serum analysis of steroid hormones and 17hydroxyprogesterone measurements. ${ }^{17,39,42}$

\section{METHODS OF PRESERVING HEIGHT IN CAH}

Improvements in glucocorticoid dosing and monitoring have shifted the focus of treatment in CAH from reducing morbidity 
and mortality to the prevention of physical and psychological impairment. $^{22}$ One obvious approach is simply more rigorous monitoring, although as noted above this does not necessarily lead to successful outcomes. One study reported on $32 \mathrm{CAH}$ patients who were provided glucocorticoid replacement therapy with close monitoring of 17-hydroxyprogesterone levels. ${ }^{22}$ Rigorous monitoring resulted in normal to low doses of glucocorticoids ( $10-15 \mathrm{mg} / \mathrm{m}^{2} /$ day) for $11.4 \pm 4.5$ years. These prevented patients from developing a cushingoid response in which excess glucocorticoid exposure leads to central obesity, striae, glucose intolerance and other symptoms. ${ }^{22}$ However, many of the patients still had slightly reduced height and bone age Z-scores (a measure of the maturity of bone), despite normal growth velocity. ${ }^{22}$ This demonstrates that androgen excess in patients with CAH due to 21-hydroxylase deficiency is the major reason for short final adult height, and glucocorticoids contribute primarily when administered at high doses.

\section{GH and GnRHa}

Given that glucocorticoid supplementation is obligatory for the treatment of $\mathrm{CAH}$, novel approaches are being developed to mitigate the complication of short final adult height in $\mathrm{CAH}^{1-4}$ GH or GnRHa are utilized, based on two underlying strategies: First, GnRHa [luteinizing hormone releasing hormone analog (LHRHa)] is administered to delay early onset of puberty that otherwise would be induced in CAH due to excess androgen. Thus, the decreased growth velocity should prevent premature epiphyseal closure. ${ }^{1-4,20,30,43}$ Second, GH enhances final adult height by counteracting the growth suppressing effects of glucocorticoids. ${ }^{20,30}$ It has been reported that growth velocity increased in children with $\mathrm{CAH}$ treated with $\mathrm{GH}$ for 1 to 4 years. ${ }^{8}$ A test cohort of seven subjects received treatment for 4 years, resulting in a 1.1 standard deviation gain in height. ${ }^{8}$

A study of 20 patients with $\mathrm{CAH}$ documented by clinical and hormonal parameters also demonstrated the beneficial effects of GH therapy (Table 1). ${ }^{4}$ Inclusion criteria were: (1) age more than 4 years, (2) bone age more than 2.0 SD advanced for their chronological age or (3) height prediction using Bayley-Pinneau tables at least 2.0 SD below their target height. Subjects were provided either GH $(n=12)$ or $\mathrm{GH}$ and GnRHa ( $\mathrm{n}=8$ ) concomitant with glucocorticoid replacement therapy. ${ }^{4}$ Each subject in the treatment group was matched at the start of GH treatment according to age, sex, bone age and type of CAH to control group of CAH patients treated only with glucocorticoid replacement. ${ }^{4}$ Treatment with GH or the combination of GH and GnRHa resulted in increased growth rate and height and reduced height deficit for bone age. ${ }^{4}$ After 1 year of GH or combination of GH and GnRHa therapy, the mean growth rate for the treatment group increased by $2.8 \mathrm{~cm} /$ year from baseline, while the group not receiving $\mathrm{GH}$ had no significant change in growth rate $(\mathrm{p}<0.0001) .{ }^{4}$ During the second year of treatment, the mean growth rate in the treatment group was $1.8 \mathrm{~cm} /$ year greater than in the control group not receiving GH or GnRHa (p < 0.001). ${ }^{4}$ Height SD score for chronological age in the treatment group at the end of 1 and 2 years of treatment improved significantly more than the non-treatment group ( $p<0.01$ after both one and two years of treatment). ${ }^{4}$ The mean predicted adult height improved from $159 \pm 11$ (baseline) to $170 \pm 7.5 \mathrm{~cm}$ after 2 years of therapy, closely approximating mean parental target height $(173 \pm 8 \mathrm{~cm}){ }^{4}$

Another study supporting the use of GH in ameliorating short stature in patients with CAH reported on $14 \mathrm{CAH}$ patients (Table 2). ${ }^{2}$ The 14 patients were provided with GH and LHRHa while on glucocorticoid replacement therapy and compared to a control group matched for CAH type, age and sex. The treatment group had significantly increased final adult height standard scores (SDS) compared with baseline height predictions $(-0.4 \pm 0.8 v s-1.5 \pm 0.9$, p $<0.0001)$; the final height discrepancy compared with baseline height discrepancy was significantly reduced $(-2.8 \pm 4.3 \mathrm{~cm} v s-10.3 \pm 4.4 \mathrm{~cm}$, $\mathrm{p}<0.0001){ }^{2}$ Among patients in the treatment group, IGF-I and IGF binding protein-3 levels did not exceed the normal range for bone age; $\mathrm{HbA}_{1 \mathrm{C}}$ and thyroid function remained normal with no adverse events reported. ${ }^{2}$

A case study involving a 4.83-year-old male who presented with advanced secondary sexual characteristics and advanced bone age (13 years) with a predicted final adult height $147 \mathrm{~cm}$ has been reported in which the patient was treated with $\mathrm{GH}^{3}$ A diagnosis of $11 \beta$-hydroxylase deficiency was suggested because of an initial 11-deoxycortisol level of 13,770 ng/dl and associated hypertension. $^{3} 11 \beta$-hydroxylase deficiency was confirmed by dexamethasone suppression test and genotyping. ${ }^{3}$ Treatment with GH and leuprolide, a GnRHa, resulted in a final height at age 12 years, which was $25.4 \mathrm{~cm}$ greater than the predicted final adult height; bone density was above average. ${ }^{3}$

Another case of $11 \beta$-hydroxylase deficiency was reported in which a 2.5-year-old Indian male was diagnosed on the basis of precocious puberty, accelerated growth (height SD + 4.4), and advanced skeletal maturation (bone age 8.4 years). ${ }^{1}$ Glucocorticoid therapy normalized the patient's hypertension, but led to progression of central precocious puberty and an increased bone age. ${ }^{1}$ Estimated final adult height before GH and GnRHa treatment was only $133.7 \mathrm{~cm}$ (mean parental predicted height $=163 \mathrm{~cm}) .{ }^{1}$ However, treatment with GnRHa improved the predicted final adult height by $3.1 \mathrm{~cm}$ over 15 months. ${ }^{1} \mathrm{GH}$ regiment was subsequently initiated, and in conjunction with GnRHa over 3.6 years, led to a final adult height of $151 \mathrm{~cm}$, an improvement of $17.3 \mathrm{~cm}$ from the initial predicted final adult height. ${ }^{1}$

\section{Aromatase Inhibitors}

Other novel treatments are less well-investigated to address short final adult height in CAH patients. Aromatase inhibitors delay bone age acceleration by preventing early epiphyseal fusion, ${ }^{44-46}$ directly addressing the primary contributor to the short final adult height in CAH patients. The mechanism by which excess androgens contribute to short final adult height involves conversion of the androgens to estrogens, the latter 
Table 1: Growth parameter summary for a treatment group that received $\mathrm{GH}(\mathrm{n}=12)$ or $\mathrm{GH}$ and $\mathrm{GnRHa}(\mathrm{n}=8)$ and a control group receiving only glucocorticoid therapy $(n=20)$. Conducted at Weill Medical College of Cornell University, Presbyterian Hospital, New York City, New York, USA ${ }^{4}$

\begin{tabular}{|c|c|c|c|}
\hline & $\begin{array}{l}\mathrm{GH} \text { and } \mathrm{GnRHa} \\
\text { treatment group } \\
\quad(n=20)\end{array}$ & $\begin{array}{l}\text { Control group } \\
\qquad(n=20)\end{array}$ & $p$-value \\
\hline Growth rate after 12 months & $7.8 \pm 1.6 \mathrm{~cm} /$ year & $5.0 \pm 2.0 \mathrm{~cm} /$ year & $<0.001$ \\
\hline Growth rate after 2 years & $6.0 \pm 1.6 \mathrm{~cm} /$ year & $4.2 \pm 2.2 \mathrm{~cm} /$ year & $<0.001$ \\
\hline Height SD score after 12 months & $1.1 \pm 1.0$ & $0.84 \pm 1.2$ & $<0.01$ \\
\hline Height SD for bone age after 12 months & $-1.4 \pm 0.9$ & $-1.7 \pm 0.9$ & $<0.0001$ \\
\hline Height SD for bone age after 2 years & $-0.67 \pm 0.68$ & $-1.7 \pm 1.2$ & $<0.0004$ \\
\hline Predicted target height after 12 months & $+6.7 \pm 2.4 \mathrm{~cm}$ & Unchanged & $<0.0001$ \\
\hline Predicted target height after 2 years & $+8.8 \pm 3.3 \mathrm{~cm}$ & Unchanged & $<0.0004$ \\
\hline
\end{tabular}

NS: Not significant

Table 2: Summary of 14 patients treated with GH and LHRHa compared to control group receiving only glucocorticoid therapy. Study conducted at department of Pediatrics, Mt Sinai School of Medicine, New York, USA

\begin{tabular}{lcc}
\hline & Untreated $(n=14)$ & Treated $(n=14)$ \\
\hline Final height $(\mathrm{cm})$ & $161.1(7.1)$ & $168.2(6.4)$ \\
Male $(\mathrm{n}=8)$ & $163.1(5.6)$ & $171.5(6.1)$ \\
Female $(\mathrm{n}=6)$ & $158.4(8.4)$ & $163.6(3.4)$ \\
Final height SDS & $-1.4(1.1)$ & $-0.4(-0.8)$ \\
Gain in height $(\mathrm{cm})$ & $-0.5(6.6)$ & $7.4(4.9)$ \\
Final height discrepancy $(\mathrm{cm})$ & $-9.6(9.2)$ & $-2.8(4.3)$ \\
\hline
\end{tabular}

being responsible for early epiphyseal fusion. Excess androgens are converted peripherally by adipose tissue into estrogens via the aromatase enzyme. ${ }^{44-46}$ Studies are now being conducted to determine whether inhibiting aromatase will prevent production of excess estrogens that are the root cause for short final adult height in CAH and other GH-related diseases. ${ }^{44-46}$ Anastrozole, a potent aromatase inhibitor, increases the adult height potential of patients on GH therapy while maintaining normal pubertal progression. ${ }^{45}$ However, trials to date have primarily involved GH-deficient patients during puberty; long-term follow-up is needed to fully elucidate the safety and efficacy of this approach. $^{44-46}$

A potential complication of aromatase inhibitors is a deleterious effect on genital function and gametogenesis. Sperm analysis on a small cohort of 11 patients who received either GH therapy alone or GH therapy combined with aromatase inhibitor therapy over 12 months was conducted to study this potential effect. ${ }^{46}$ Sperm motility and morphology in both groups showed to be similar to a control group of healthy males $(\mathrm{n}=11)^{46}$

\section{SUMMARY AND CONCLUSION}

Treating $\mathrm{CAH}$ requires exogenous administration of glucocorticoids, which are associated with a reduction in final adult height. Use of synthetic glucocorticoids, e.g. prednisolone and dexamethasone, has been associated with a greater reduction of final adult height than hydrocortisone alone. ${ }^{15,17,39}$ In order to compensate for the growth suppressive effect of glucocorticoid administration, a treatment strategy involving GnRHa has proven to be effective in delaying precocious puberty and early epiphyseal advancement that inevitably results from androgen excess in CAH; GnRH subsequently promotes normal growth velocities through GH. ${ }^{1-4}$ This strategy has increased the final adult height in $\mathrm{CAH}$ patients compared to glucocorticoid treatment alone, often bringing patients near their mean parental predicted height. Among CAH patients who received GH and GnRHa treatments, IGF-I and IGF binding protein-3 levels did not exceed the normal range for bone age; $\mathrm{HbA}_{1 \mathrm{C}}$ and thyroid function remained normal. ${ }^{1-4}$ Another treatment strategy involves aromatase inhibition to reduce the conversion of excess androgens to estrogens and, hence, prevent estrogen-dependent epiphyseal fusion. Anastrozole administered for 2 to 3 years increases the adult height potential of patients on GH therapy while maintaining normal pubertal progression. ${ }^{45}$ Randomized control trials and long-term followup are needed to determine the safety and efficacy of this approach in $\mathrm{CAH} .{ }^{44,45}$

\section{ACKNOWLEDGMENTS}

We would like to thank Dr Joe Leigh Simpson (Florida International University Herbert Wertheim College of Medicine) and Dr Helen Tempest (Florida International University Herbert Wertheim College of Medicine) for their general support.

\section{REFERENCES}

1. Bajpai A, Kabra M, Menon PS. Combination growth hormone and gonadotropin releasing hormone analog therapy in 11 betahydroxylase deficiency. J Pediatr Endocrinol Metab 2006;19: 855-57. 
2. Lin-Su K, Vogiatzi MG, Marshall I, Harbison MD, Macapagal $\mathrm{MC}$, et al. Treatment with growth hormone and luteinizing hormone releasing hormone analog improves final adult height in children with congenital adrenal hyperplasia. J Clin Endocrinol Metab 2005;90:3318-25.

3. Chalmers LJ, Casas L, New MI, Blackett PR. Prolongation of growth by treatment of 11-hydroxylase deficiency with depotleuprolide, growth hormone, and hydrocortisone. J Pediatr Endocrinol Metab 2006;19:1251-55.

4. Quintos JB, Vogiatzi MG, Harbison MD, New MI. Growth hormone therapy alone or in combination with gonadotropinreleasing hormone analog therapy to improve the height deficit in children with congenital adrenal hyperplasia. J Clin Endocrinol Metab 2001;86:1511-17.

5. New MI, Gertner JM, Speiser PW, Del Balzo P. Growth and final height in classical and nonclassical 21-hydroxylase deficiency. J Endocrinol Invest 1989;12:91-95.

6. New MI. Factors determining final height in congenital adrenal hyperplasia. J Pediatr Endocrinol Metab 2001;14 (Suppl 2): 933-37.

7. Forest MG. Recent advances in the diagnosis and management of congenital adrenal hyperplasia due to 21-hydroxylase deficiency. Hum Reprod Update 2004;10:469-85.

8. Migeon CJ, Wisniewski AB. Congenital adrenal hyperplasia owing to 21-hydroxylase deficiency: Growth, development and therapeutic considerations. Endocrinol Metab Clin North Am 2001;30:193-206.

9. Nimkarn S, New MI. Congenital adrenal hyperplasia due to 21-hydroxylase deficiency: A paradigm for prenatal diagnosis and treatment. Ann N Y Acad Sci 2010;1192:5-11.

10. Bonfig W, Pozza SB, Schmidt H, Pagel P, Knorr D, et al. Hydrocortisone dosing during puberty in patients with classical congenital adrenal hyperplasia: An evidence-based recommendation. J Clin Endocrinol Metab 2009;94:3882-88.

11. Hauffa BP, Winter A, Stolecke H. Treatment and disease effects on short-term growth and adult height in children and adolescents with 21-hydroxylase deficiency. Klin Padiatr 1997;209:71-77.

12. Rivkees SA, Crawford JD. Dexamethasone treatment of virilizing congenital adrenal hyperplasia: The ability to achieve normal growth. Pediatrics 2000;106:767-73.

13. Stikkelbroeck NM, Van't Hof-Grootenboer BA, Hermus AR, Otten BJ, Van't Hof MA. Growth inhibition by glucocorticoid treatment in salt wasting 21-hydroxylase deficiency: In early infancy and (pre)puberty. J Clin Endocrinol Metab 2003;88: 3525-30.

14. Rasat R, Espiner EA, Abbott GD. Growth patterns and outcomes in congenital adrenal hyperplasia. Effect of chronic treatment regimens. NZ Med J 1995;108:311-14.

15. Ercan O, Hatemi S, Kutlu E, Turan N. Effect of treatment on growth in congenital adrenal hyperplasia. Indian J Pediatr 2000;67:783-89.

16. DiMartino-Nardi J, Stoner E, O’Connell A, New MI. The effect of treatment of final height in classical congenital adrenal hyperplasia (CAH). Acta Endocrinol Suppl (Copenh) 1986;279: 305-14.

17. Bonfig W, Bechtold S, Schmidt H, Knorr D, Schwarz HP. Reduced final height outcome in congenital adrenal hyperplasia under prednisone treatment: Deceleration of growth velocity during puberty. J Clin Endocrinol Metab 2007;92:1635-39.

18. Aycan Z, Ocal G, Berberoglu M, Cetinkaya E, Adiyaman P, et al. Experience with long-term glucocorticoid treatment in congenital adrenal hyperplasia: Growth pattern compared with genetic height potential. J Pediatr Endocrinol Metab 2006;19: 245-51.
19. Jacobs DR, Van Der Poll J, Gabrilove JL, Soffer LJ. 17 alphahydroxyprogesterone-a salt-losing steroid: Relation to congenital adrenal hyperplasia. J Clin Endocrinol Metab 1961;21:909-22.

20. Allen DB, Julius JR, Breen TJ, Attie KM. Treatment of glucocorticoid-induced growth suppression with growth hormone. National Cooperative Growth Study. J Clin Endocrinol Metab 1998;83:2824-29.

21. Mora S, Saggion F, Russo G, Weber G, Bellini A, et al. Bone density in young patients with congenital adrenal hyperplasia. Bone 1996;18:337-40.

22. Girgis R, Winter JS. The effects of glucocorticoid replacement therapy on growth, bone mineral density, and bone turnover markers in children with congenital adrenal hyperplasia. J Clin Endocrinol Metab 1997;82:3926-29.

23. Lin-Su K, New MI. Effects of adrenal steroids on the bone metabolism of children with congenital adrenal hyperplasia. Ann NY Acad Sci 2007;1117:345-51.

24. Cameron FJ, Kaymakci B, Byrt EA, Ebeling PR, Warne GL, et al. Bone mineral density and body composition in congenital adrenal hyperplasia. J Clin Endocrinol Metab 1995;80:223843.

25. Guo CY, Weetman AP, Eastell R. Bone turnover and bone mineral density in patients with congenital adrenal hyperplasia. Clin Endocrinol (Oxf) 1996;45:535-41.

26. Gussinye M, Carrascosa A, Potau N, Enrubia M, Vicens-Calvet $\mathrm{E}$, et al. Bone mineral density in prepubertal and in adolescent and young adult patients with the salt-wasting form of congenital adrenal hyperplasia. Pediatrics 1997;100:671-74.

27. Nguyen AT, Brown JJ, Warne GL. Growth in congenital adrenal hyperplasia. Indian J Pediatr 2006;73:89-93.

28. Eugster EA, Dimeglio LA, Wright JC, Freidenberg GR, Seshadri R, et al. Height outcome in congenital adrenal hyperplasia caused by 21-hydroxylase deficiency: A metaanalysis. J Pediatr 2001;138:26-32.

29. Gallagher MP, Levine LS, Oberfield SE. A review of the effects of therapy on growth and bone mineralization in children with congenital adrenal hyperplasia. Growth hormone and IGF research: Official Journal of the Growth Hormone Research Society and the International IGF Research Society 2005;15 (Suppl A):S26-30.

30. Kovacs G, Fine RN, Worgall S, Schaefer F, Hunziker EB, et al. Growth hormone prevents steroid-induced growth depression in health and uremia. Kidney Int 1991;40:1032-40.

31. Yu AC, Grant DB. Adult height in women with early-treated congenital adrenal hyperplasia (21-hydroxylase type): Relation to body mass index in earlier childhood. Acta Paediatr 1995;84:899-903.

32. Weintrob N, Dickerman Z, Sprecher E, Galatzer A, Pertzelan A. Non-classical 21-hydroxylase deficiency in infancy and childhood: The effect of time of initiation of therapy on puberty and final height. Eur J Endocrinol 1997;136:188-95.

33. Urban MD, Lee PA, Migeon CJ. Adult height and fertility in men with congenital virilizing adrenal hyperplasia. N Engl J Med 1978;299:1392-96.

34. Speiser PW. Growth and development: Congenital adrenal hyperplasia-glucocorticoids and height. Nat Rev Endocrinol 2010;6:14-15.

35. Muirhead S, Sellers EA, Guyda H. Indicators of adult height outcome in classical 21-hydroxylase deficiency congenital adrenal hyperplasia. J Pediatr 2002;141:247-52.

36. Kolouskova S, Zemkova D, Snajderova M, Lebl J (Growth and adult height in patients with congenital adrenal hyperplasia). Cas Lek Cesk 1995;134:689-91. 
37. Kirkland RT, Keenan BS, Holcombe JH, Kirkland JL, Clayton GW. The effect of therapy on mature height in congenital adrenal hyperplasia. J Clin Endocrinol Metab 1978;47:1320-24.

38. Jaaskelainen J, Voutilainen R. Growth of patients with 21-hydroxylase deficiency: An analysis of the factors influencing adult height. Pediatr Res 1997;41:30-33.

39. Bajpai A, Pandey RM, Kabra M, Menon PS. Growth pattern and final height in 21-hydroxylase deficiency. Indian Pediatr 2007;44:771-73.

40. Brunelli VL, Russo G, Bertelloni S, Gargantini L, Balducci R, et al. Final height in congenital adrenal hyperplasia due to 21-hydroxylase deficiency: The Italian experience. J Pediatr Endocrinol Metab 2003;16(Suppl 2):277-83.

41. Devesa J, Barros MG, Gondar M, Tresguerres JA, Arce V. Regulation of hypothalamic somatostatin by glucocorticoids. J Steroid Biochem Mol Biol 1995;53:277-82.

42. Einaudi S, Lala R, Corrias A, Matarazzo P, Pagliardini S, et al. Auxological and biochemical parameters in assessing treatment of infants and toddlers with congenital adrenal hyperplasia due to 21-hydroxylase deficiency. J Pediatr Endocrinol 1993;6:173-78.

43. Orio Hernandez M, Yebra Yebra J, Bezanilla Lopez C, Gracia Bouthelier R. 11beta-hydroxylase deficiency: Improvement of final height with growth hormone and gonadotropin-releasing hormone analog. An Pediatr (Barc) 2007;67:153-56.

44. Mauras N. Strategies for maximizing growth in puberty in children with short stature. Endocrinol Metab Clin North Am 2009;38:613-24.

45. Mauras N, Gonzalez de Pijem L, Hsiang HY, Desrosiers P, Rapaport R, et al. Anastrozole increases predicted adult height of short adolescent males treated with growth hormone: A randomized, placebo-controlled, multicenter trial for one to three years. J Clin Endocrinol Metab 2008;93:823-31.

46. Mauras N, Bell J, Snow BG, Winslow KL. Sperm analysis in growth hormone-deficient adolescents previously treated with an aromatase inhibitor: Comparison with normal controls. Fertil Steril 2005;84:239-42. 